OPEN ACCESS

Edited by:

Renheng Wang,

Shenzhen University, China

Reviewed by:

Huarong Xia,

Nanyang Technological University,

Singapore

Qiulong Wei,

Xiamen University, China

${ }^{*}$ Correspondence:

Haibo L

lihaibo@nxu.edu.cn

Specialty section:

This article was submitted to

Electrochemical Energy Conversion

and Storage,

a section of the journal

Frontiers in Energy Research

Received: 22 September 2021

Accepted: 14 October 2021

Published: 10 November 2021

Citation:

Guo M and LiH (2021) The Hydrolyzed Mil-88B(Fe) With Improved Surface Area for High-Capacity Lithium

Ion Battery.

Front. Energy Res. 9:781008. doi: 10.3389/fenrg.2021.781008

\section{The Hydrolyzed Mil-88B(Fe) With Improved Surface Area for High-Capacity Lithium Ion Battery}

\author{
Mingxuan Guo and Haibo $\mathrm{Li}^{*}$ \\ Ningxia Key Laboratory of Photovoltaic Materials, Ningxia University, Yinchuan, China
}

In this work, Mil-88B $(\mathrm{Fe})$ is modified by a facile hydrolysis method for high-performance lithium ion battery (LIB). The hydrolyzed Mil-88B(Fe) [H-Mil-88B(Fe)] heritages the spindlelike shape of Mil-88B(Fe) and forms a porous structure, which possesses relatively high specific surface area $\left(427.86 \mathrm{~m}^{2} \mathrm{~g}^{-1}\right)$. It is 15 times higher than that of pristine Mil-88B(Fe). As anode for LIB, it reaches to high specific capacity of $600.1 \mathrm{mAh} \mathrm{g}^{-1}$ after 100 cycles at $100 \mathrm{~mA} \mathrm{~g}^{-1}$, while it is $312.5 \mathrm{mAh} \mathrm{g}^{-1}$ for pure Mil-88B(Fe). Furthermore, the kinetic analysis on $i=a v^{b}$ reveals that the b value of $\mathrm{H}-\mathrm{Mil}-88 \mathrm{~B}(\mathrm{Fe})$ is 0.888 , which suggests the mixed contribution from the diffusion and capacity reactions. Furthermore, the capacitance contribution fractions of $\mathrm{H}-\mathrm{Mil}-88 \mathrm{~B}(\mathrm{Fe})$ are $47.6 \%, 53.28 \%, 56.88 \%$, $74.68 \%$, and $69.14 \%$ at the sweep rate of $0.2,0.4,0.6,0.8,1.0 \mathrm{mV} \mathrm{s}^{-1}$, respectively, demonstrating a capacitance-dominated charge storage process at fast charging rates.

Keywords: MIL-88B, Li ion battery, anode material, electrochemical performance, specific capacity

\section{INTRODUCTION}

With the increasing popularity of portable electronic products and grid energy storage systems, the LIB with high energy density and power density is of great importance (Du et al., 2020; Wei et al., 2020; Zhang et al., 2021a; Chang et al., 2021). The natural graphite as the commercial LIB anode has shown advantages of well stability and abundant resource (Deng et al., 2017; Li et al., 2018; Ming et al., 2018; Huang et al., 2020). However, the low theory specific capacity $\left(372 \mathrm{mAh} \mathrm{g}^{-1}\right)$ becomes the biggest obstacle (Wang et al., 2017; Xu et al., 2017; Xi et al., 2019; Liu et al., 2020).

The metal-organic frameworks (MOFs), a self-assembled organic-inorganic hybrid (Yang et al,, 2018; Wang et al., 2019a; Wang et al., 2019b), are regarded as promising materials that are applied in the domains of catalysis (Rao and Mandal, 2019; Wang et al., 2020), energy storage (Xu et al., 2018a; Dou et al., 2019), and gas storage (Xu et al., 2018b) due to high chemical stability (Chen et al., 2015), huge specific surface areas (Luo et al., 2016), controllable structure (Hu et al., 2021), and abundant resource (Du et al., 2011). Among them, the Mil- $88 \mathrm{~B}(\mathrm{Fe})$ with $\mathrm{Fe}$ as the core metal ion and terephthalic acid as the organic ligand is an important member of the Fe-MOF family (Shen et al., 2021; Wang et al., 2021; Yang et al., 2021). Remarkably, the Mil-88B(Fe) derivatives have emerged as environmentally benign materials for energy storage device (Pan et al., 2018; Zhang et al., 2021b). As an LIB anode, the homogenous structure of Mil- $88 \mathrm{~B}(\mathrm{Fe})$ ensures the uniform distribution of the accessible transition metal $\left(\mathrm{Fe}_{3} \mathrm{O}\right)$ clusters as active sites throughout the electrode reaction, leading to a prominent performance of LIB (Férey et al., 2007). In the charge/discharge process, both the $\mathrm{Fe}_{3} \mathrm{O}$ cluster and the organic ligands contribute to the capacity. The $\mathrm{Fe}^{3+}$ is reduced to $\mathrm{Fe}^{2+}$, and meanwhile, the organic ligands can accommodate partial $\mathrm{Li}^{+}$at the discharge process (Shen et al., 2017). In 2007, Férey et al. first reported the synthesis of MIL-53 as the positive electrode 
in LIB. Unfortunately, the specific capacity $\left(75 \mathrm{mAh} \mathrm{g}^{-1}\right)$ and cycling stability were below the expectation (Wang and Cao, 2008). Actually, the low conductivity restricts the LIB performance of pure Mil-88B(Fe) electrode (Zhang et al., 2017). To solve this issue, Zhang et al. synthesized Mil-53@ reduced graphene oxide composite for LIB anode. It exhibited high specific capacity of $550 \mathrm{mAh} \mathrm{g}^{-1}$ at $100 \mathrm{~mA} \mathrm{~g}^{-1}$ after 100 cycles. The improved performance is ascribed to the presence of graphene, which acts as a conductive bridge to enhance the bulk conductivity of the whole electrode (Jin et al., 2017). Besides the graphene, Jin et al. prepared $\mathrm{Fe}_{3} \mathrm{O}_{4} / \mathrm{C}$ composite by sintering the Mil- $88 \mathrm{~B}(\mathrm{Fe})$ under $\mathrm{Ar}$ atmosphere. The $\mathrm{Fe}_{3} \mathrm{O}_{4} / \mathrm{C}$ manifests the high specific capacity of $928 \mathrm{mAh} \mathrm{g}^{-1}$ at $0.5^{\circ} \mathrm{C}$ after 200 cycles, which are attributed to the improved electrical conductivity and electrochemical behavior originating from the carbon coatings (Shen et al., 2017). Interestingly, Shen et al. developed a polyhedral nanorod structure, which was derived from Mil$88 \mathrm{~B}(\mathrm{Fe})$ for $\mathrm{LIB}$ anode. It exhibited reversible capacity of $744.5 \mathrm{mAh} \mathrm{g}^{-1}$ at $60 \mathrm{~mA} \mathrm{~g}^{-1}$ after 400 cycles. The nanorods shorten the $\mathrm{Li}^{+}$diffusion length, which promotes the reaction kinetics (Guo and Li, 2021).

In this work, we attempt to trigger the water hydrolysis on Mil$88 \mathrm{~B}(\mathrm{Fe})$ toward the enhanced specific surface area (SSA). When employed as anode for LIB, the huge SSA of the hydrolyzed Mil$88 \mathrm{~B}(\mathrm{Fe})$ [H-Mil- $88 \mathrm{~B}(\mathrm{Fe})]$ promise to provide abundant redox sites, and meanwhile, the spindle-like nanostructure benefits to relive the volume changes. As a result, the $\mathrm{H}-\mathrm{Mil}-88 \mathrm{~B}(\mathrm{Fe})$ verifies the superior LIB performance including high reversible capacity, moderate rate capability, and cyclic stability.

\section{EXPERIMENTAL SECTION}

\section{Preparation of Mil-88B(Fe)}

The uniform Mil-88B(Fe) was prepared by a facile solvothermal method. Briefly, $0.1661 \mathrm{~g}$ of terephthalic acid (TPA) and $0.2703 \mathrm{~g} \mathrm{FeCl}_{3} \cdot 6 \mathrm{H}_{2} \mathrm{O}$ was added into $10 \mathrm{ml}$ of $\mathrm{N}, \mathrm{N}$ dimethylformamide (DMF) under vigorous stirring at room temperature to obtain solutions $\mathrm{A}$ and $\mathrm{B}$, respectively. After that, solutions $A$ and $B$ were mixed thoroughly, and then transferred into $15-\mathrm{ml}$ Teflon-lined stainless autoclaves and followed by heating at $150^{\circ} \mathrm{C}$ for $150 \mathrm{~min}$. After natural cooling, the sediments were washed with DMF and ethanol. Finally, it was collected by centrifugation at $8,000 \mathrm{rpm} / \mathrm{min}$ for $5 \mathrm{~min}$, and then dried at $80^{\circ} \mathrm{C}$ in a vacuum oven overnight. The brick-red Mil-88B(Fe) powder was obtained successfully.

\section{Preparation of $\mathrm{H}-\mathrm{Mil}-\mathbf{8 8 B}(\mathrm{Fe})$}

Mil-88B(Fe) $(40 \mathrm{mg})$ was dissolved in $14 \mathrm{ml}$ of ethanol under ultrasound for $20 \mathrm{~min}$. Then $6 \mathrm{ml}$ of deionized water (DI) was added into the solution. After extra magnetic stirring for $10 \mathrm{~min}$, the mixed solution was heated in an oil bath under gentle stirring at $90^{\circ} \mathrm{C}$ for $1 \mathrm{~h}$. Subsequently, the precipitate was collected by centrifugation and washed with ethanol three times. Finally, the product was dried overnight in a vacuum oven at $80^{\circ} \mathrm{C}$.

\section{Electrochemical Measurements}

The working electrode is prepared by a typical method that was described in our previous work (Come et al., 2011). In brief, the Mil- $88 \mathrm{~B}(\mathrm{Fe}) / \mathrm{H}-\mathrm{Mil}-88 \mathrm{~B}(\mathrm{Fe})$ is employed as an active material, which is completely mixed with acetylene black and polyvinylidene fluoride (PVDF) to prepare the slurry. Most importantly, the mass ratio of active material, acetylene black, and PVDF was set as 8:1:1. After that, the slurry was uniformly coated on the nickel foam $(\varnothing 16 \mathrm{~mm})$ and sent to an oven to get rid of impurities. The coin-cell batteries (CR 2032) were assembled in an argon-filled glove box where the as-prepared electrodes and lithium metal was utilized as the anode and counter electrode, respectively. Furthermore, the $\mathrm{LiPF}_{6} /$ ethylene carbonate (EC)/dimethyl carbonate (DMC) mixed solution and the Celgard membrane (Celgard 2,500, Ø19 mm) was used as electrolyte and separator, respectively. The electrochemical performance [cyclic voltammograms (CVs) and electrochemical impedance spectra (EIS)] was explored by an electrochemical workstation (Princeton Applied Research PARSTAT 3000A-DX, United States). The galvanostatic charge/discharge (GCD) test was examined on a battery test system (LANHE CT 2001A, China) in a working voltage of 0.001-3 V (vs. $\mathrm{Li} / \mathrm{Li}^{+}$). Moreover, the capacitance contribution was calculated by a classical method. During the charge/discharge processes, the $\mathrm{Li}^{+}$extraction/insertion leads to a response of the redox peak extracted from the $\mathrm{CV}$ curve at different scanning rates (Shen et al., 2018). The relationship between the current (i) and sweep rates (v) follows Eq. 1 (Ma et al., 2013):

$$
i=a v^{b}
$$

where $\mathrm{a}$ and $\mathrm{b}$ are adjustable values.

Furthermore, the total current can be divided into two parts. One is considered to vary with the sweep rate $\left(\mathrm{k}_{1} \mathrm{v}\right)$, and another relates to the square root of the sweep rate $\left(\mathrm{k}_{2} \mathrm{v}^{1 / 2}\right)$, as shown in Eq. 2 (Ma et al., 2013):

$$
i(v)=K_{1} v+K_{2} v^{1 / 2}
$$

where $\mathrm{k}_{1}$ and $\mathrm{k}_{2}$ are constants at a particular voltage, and the value of $\mathrm{k}_{1} \mathrm{v}$ represent the capacitance contribution.

\section{DISCUSSION}

Figure 1A shows the X-ray diffraction (XRD, Rigaku Smart Lab, Japan) patterns of Mil-88B(Fe) and H-Mil-88B(Fe). Essentially, the XRD pattern of $\mathrm{Mil}-88 \mathrm{~B}(\mathrm{Fe})$ displays the standard characteristic peaks, which are indexed in the hexagonal space group for p62c (Zhu et al., 2021). Among these peaks, the peak at $9.51,9.72,12.67,14.1,16.29,16.68,17.12,18.97$, and $22.15^{\circ}$ represents the (101), (002), (102), (110), (200), (103), (112), (202), and (211) planes of Mil- $88 \mathrm{~B}(\mathrm{Fe})$, respectively. In terms of the XRD pattern of $\mathrm{H}-\mathrm{Mil}-88 \mathrm{~B}(\mathrm{Fe})$, the peak at around $9.51^{\circ}$ becomes weak. Significantly, two new sharp characteristic peaks appear at $9.08^{\circ}$ and $10.66^{\circ}$, which are ascribed to the variation of the lattice (Zhu et al., 2021). Accordingly, the crystal structure diagrams of $\mathrm{Mil}-88 \mathrm{~B}(\mathrm{Fe})$ and $\mathrm{H}-\mathrm{Mil}-88 \mathrm{~B}(\mathrm{Fe})$ are given in 

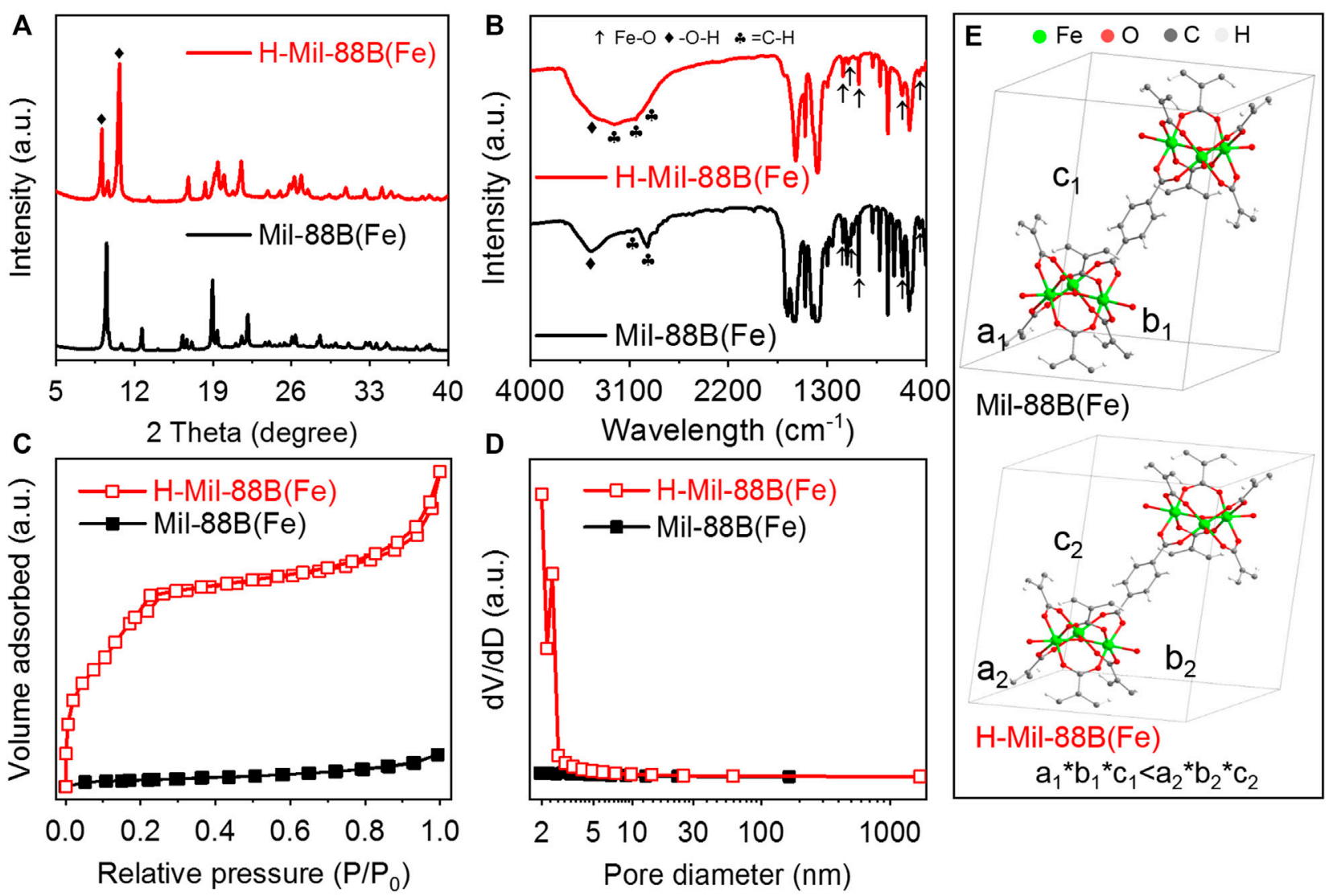

FIGURE 1 | The (A) X-ray diffraction (XRD) patterns, (B) FT-IR curves, (C) $\mathrm{N}_{2}$ adsorption/desorption isotherms, (D) pore size distributions, and (E) crystal structure diagram of $\mathrm{Mil}-88 \mathrm{~B}(\mathrm{Fe})$ and $\mathrm{H}-\mathrm{Mil}-88 \mathrm{~B}(\mathrm{Fe})$

Figure 1E. Figure 1B draws the Fourier transform infrared spectra (FTIR, PerkinElmer Spectrum Two, United States) of Mil-88B(Fe) and H-Mil-88B(Fe). Basically, both curves are quite similar. In the region of $1,300-400 \mathrm{~cm}^{-1}$, the peaks near $1,159.79$, $1,111.5,1,016.82,622.71$, and $465.61 \mathrm{~cm}^{-1}$ are probably attributed to the stretching vibrations of $\mathrm{Fe}-\mathrm{O}$ bonds. Compared with Mil$88 \mathrm{~B}(\mathrm{Fe})$, the strength of $\mathrm{Fe}-\mathrm{O}$ bonds relating to $\mathrm{H}-\mathrm{Mil}-88 \mathrm{~B}(\mathrm{Fe})$ becomes weaker after hydrolysis, implying the breaking of $\mathrm{Fe}-\mathrm{O}$ bonds. In the medium wavelength region $\left(4,000-1,300 \mathrm{~cm}^{-1}\right)$, regarding $\mathrm{Mil}-88 \mathrm{~B}(\mathrm{Fe})$, the stretching vibrations of $=\mathrm{C}-\mathrm{H}$ bonds and $-\mathrm{O}-\mathrm{H}$ bonds cause the peak emerging at 2,936.15 and $3,451 \mathrm{~cm}^{-1}$, respectively (Guo and Li, 2021; Xia et al., 2021). After hydrolysis, corresponding to the $\mathrm{H}-\mathrm{Mil}-88 \mathrm{~B}(\mathrm{Fe})$, the peak at $3,046.76$ and $3,336.47 \mathrm{~cm}^{-1}$ are regarded as $\mathrm{C}-\mathrm{H}$ and $\mathrm{O}-\mathrm{H}$ bonds, respectively. As a result, the hydrolysis results in the breaking of $\mathrm{Fe}-\mathrm{O}$ bonds and thereby exposing more $=\mathrm{C}-\mathrm{H}$ groups. Figures 1C, D draw the $\mathrm{N}_{2}$ adsorption/desorption curve and $\mathrm{BJH}$ (Barrett-Joyner-Halenda) pore size distribution of two samples. They were measured by a surface area analyzer (JWGB JWBK200C, China) relying on the single-point Brunauer-Emmett-Teller (BET) method. Both the Mil-88B(Fe) and $\mathrm{H}-\mathrm{Mil}-88 \mathrm{~B}(\mathrm{Fe})$ exhibit a typical type-IV isotherm with a hysteresis loop arising at medium pressure range, which verifies the existence of considerable mesopores. As a result, the SSA is
27.761 and $427.862 \mathrm{~m}^{2} \mathrm{~g}^{-1}$, corresponding to Mil-88B(Fe) and $\mathrm{H}-\mathrm{Mil}-88 \mathrm{~B}(\mathrm{Fe})$, respectively. By comparing with $\mathrm{Mil}-88 \mathrm{~B}(\mathrm{Fe})$, a dominant peak focusing at $2.5 \mathrm{~nm}$ is examined from the pore size distribution curve of H-Mil-88B(Fe) (Figure 1D). The significantly improved SSA is ascribed to the hydrolysis, which benefits to create pores on $\mathrm{Mil}-88 \mathrm{~B}(\mathrm{Fe})$ by breaking the $\mathrm{Fe}-\mathrm{O}$ bonds. Furthermore, the huge SSA is deductive to bring more active sites to accommodate $\mathrm{Li}^{+}$, causing high specific capacity.

The morphology of $\mathrm{Mil}-88 \mathrm{~B}(\mathrm{Fe})$ and $\mathrm{H}-\mathrm{Mil}-88 \mathrm{~B}(\mathrm{Fe})$ was investigated by scanning electron microscope (SEM, Hitachi SU5000, Japan) and transmission electron microscopy (TEM, FEI Talos 200s, United States). As shown in Figures 2A, C relating to the SEM and TEM image of Mil-88B(Fe), respectively, $\mathrm{Mil}-88 \mathrm{~B}(\mathrm{Fe})$ displays a uniform spindle-like structure with an average size of $1 \mu \mathrm{m}$. Moreover, the surface of $\mathrm{Mil}-88 \mathrm{~B}(\mathrm{Fe})$ is quite smooth. After hydrolysis, H-Mil- $88 \mathrm{~B}(\mathrm{Fe})$ (Figures 2B,D) basically exhibits a hollowed spindle-like structure with relatively rough surface. Furthermore, plenty of pores can be clearly captured in the inset of Figure 2D, which is favorable for promoting ion diffusion. Thus, the hollowed spindlelike structure provides a significant basis toward the high SSA.

Figures 3A, B illustrate the first five successive CV curves of Mil- $88 \mathrm{~B}(\mathrm{Fe})$ and $\mathrm{H}-\mathrm{Mil}-88 \mathrm{~B}(\mathrm{Fe})$ within the voltage window ranging from 0.001 to $3 \mathrm{~V}$ at $0.1 \mathrm{mV} \mathrm{s}^{-1}$. Essentially, they both 


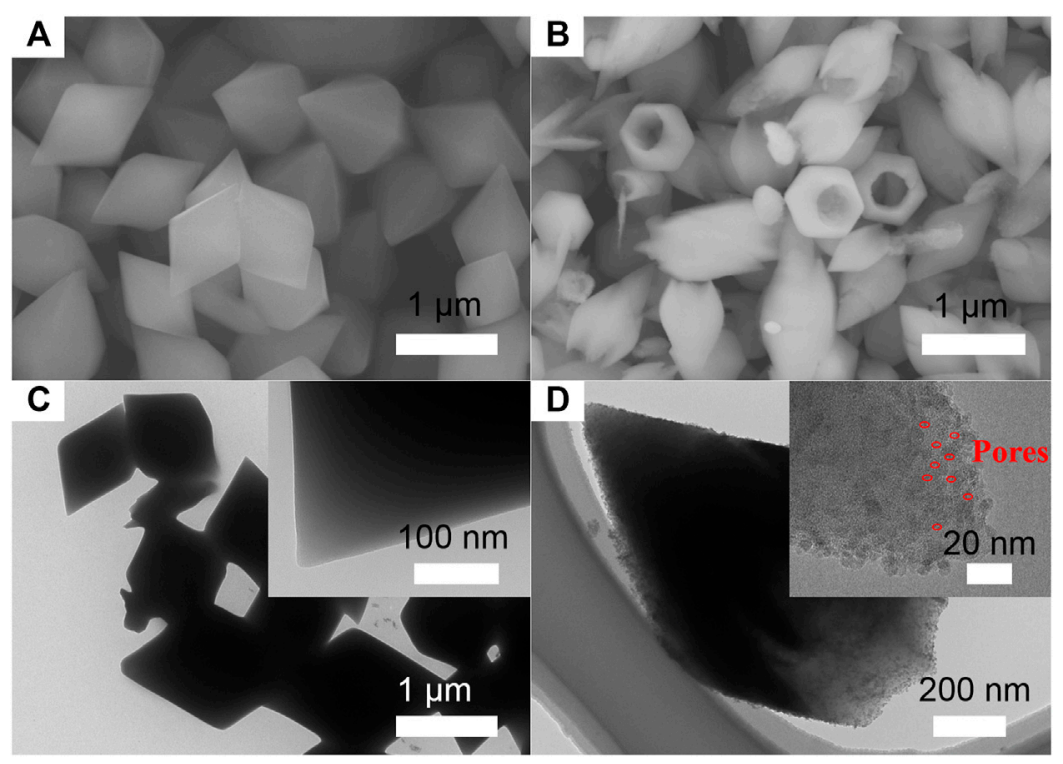

FIGURE 2 | The scanning electron microscope (SEM) pictures of Mil-88B(Fe) (A) and H-Mil-88B(Fe) (B). The transmission electron microscopy (TEM) images of Mil$88 \mathrm{~B}(\mathrm{Fe})$ (C) and $\mathrm{H}-\mathrm{Mil}-88 \mathrm{~B}(\mathrm{Fe})$ (D).
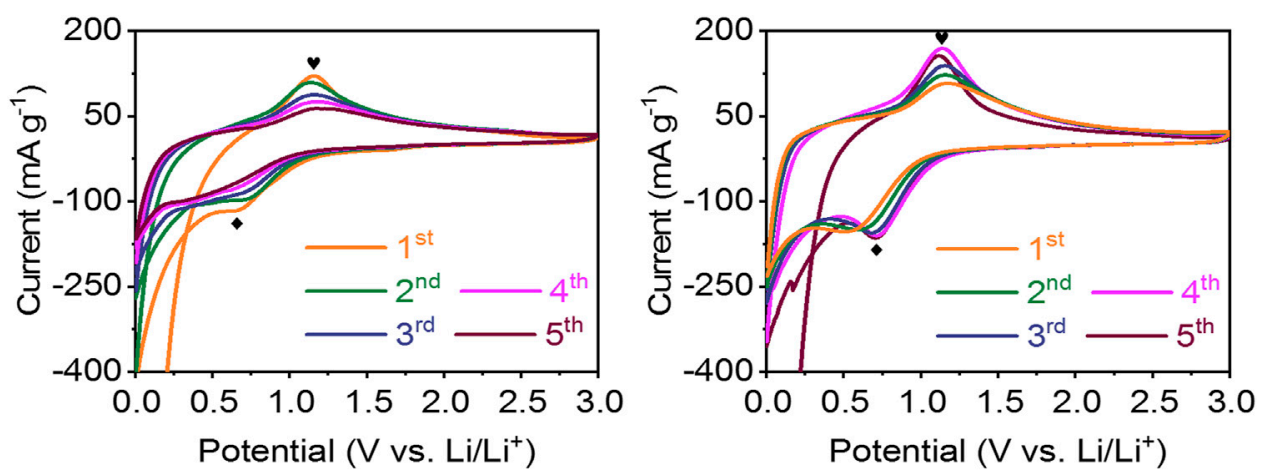

FIGURE 3 | Cyclic voltammogram (CV) curves of (A) H-Mil-88B(Fe) and (B) Mil-88B(Fe).

have one pair of redox peaks relating to the conversion between $\mathrm{Fe}^{2+}$ and $\mathrm{Fe}^{3+}$, in which the oxidation peak and reduction peak locate at 1.11 and $0.71 \mathrm{~V}$, respectively (Jin et al., 2017; Guo and $\mathrm{Li}, 2021)$. Upon the increase in cycle number, two peaks are going to stabilize, indicating the reversibility of the electrode. On the other hand, the CV curve of the first cycle is, to some extent, deforming due to the activation of the electrode and the formation of the solid electrolyte interface (SEI) film. Moreover, the area extracted from the $\mathrm{CV}$ curve of $\mathrm{H}-\mathrm{Mil}-88 \mathrm{~B}(\mathrm{Fe})$ is higher than that $\mathrm{Mil}-88 \mathrm{~B}(\mathrm{Fe})$ at each scan rate, realizing the higher specific capacity.

Figure 4A shows the GCD curves of H-Mil-88B $(\mathrm{Fe})$ for the 1 st, 2nd, 20th, and 100th cycles at a current density of $100 \mathrm{~mA}$ $\mathrm{g}^{-1}$. In the first cycle, the $\mathrm{H}-\mathrm{Mil}-88 \mathrm{~B}(\mathrm{Fe})$ electrode delivers a discharge capacity of $1,615.7 \mathrm{mAh} \mathrm{g}^{-1}$ and charge capacity of $967.9 \mathrm{mAh} \mathrm{g}^{-1}$, suggesting that the Coulombic efficiency (CE) is
59.9\%. The low CE and irreversible capacity loss are originated from the generation of SEI film and irreversible redox reaction. On the other hand, the first discharge capacity is much higher than the theoretical capacity of Mil-88B(Fe) (900.4 $\left.\mathrm{mAh} \mathrm{g}^{-1}\right)$, which is presumably due to the movable ions in both of the electrolyte and electrodes for Li ion storage (Shang et al., 2021). Moreover, two voltage platforms are observed at $\sim 0.7$ and $\sim$ $1.2 \mathrm{~V}$ from the charge and discharge curve, respectively, which are consistent with the redox peaks of the $\mathrm{CV}$ curve. Importantly, the GCD curves of the 20th and 100th cycles are almost a coincidence, ensuring the enhanced reversibility of the H-Mil- $88 \mathrm{~B}(\mathrm{Fe})$ electrode. Figure 4B illuminates the cycling behavior of the Mil- $88 \mathrm{~B}(\mathrm{Fe})$ and $\mathrm{H}-\mathrm{Mil}-88 \mathrm{~B}(\mathrm{Fe})$ electrodes at the current density of $100 \mathrm{~mA} \mathrm{~g}^{-1}$. By activation, both electrodes exhibit relatively good cycling stability after 10 cycles. Remarkably, the specific capacity of 

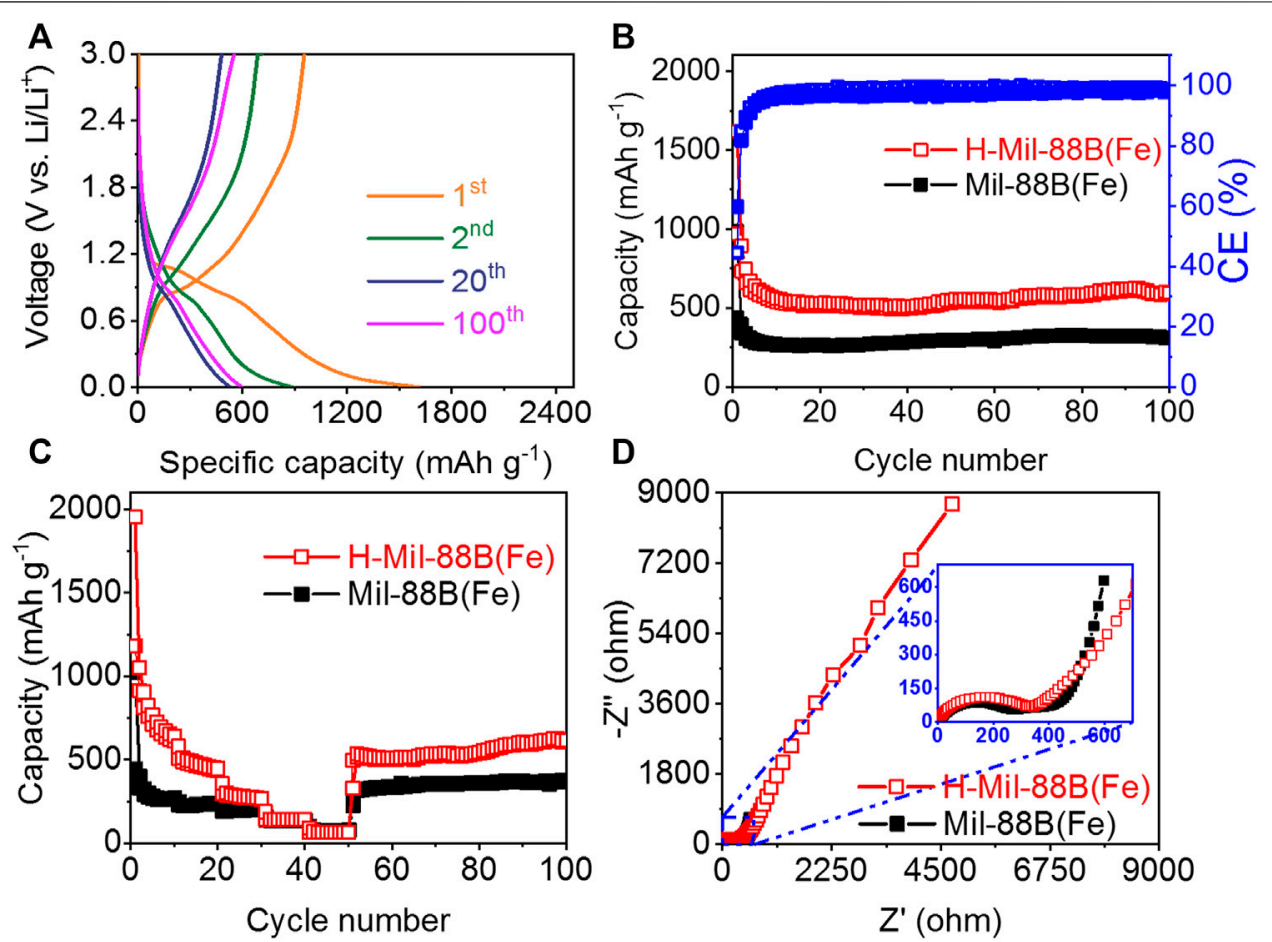

FIGURE 4 | (A) The charge-discharge curves of the H-Mil-88B(Fe) electrode at a rate of $100 \mathrm{~mA} \mathrm{~g}^{-1}$. (B) The cycling performance and corresponding Coulombic efficiency (CE) of $\mathrm{H}-\mathrm{Mil}-88 \mathrm{~B}(\mathrm{Fe})$ and Mil-88B(Fe) at a current density of $100 \mathrm{~mA} \mathrm{~g}^{-1}$. (C) The rate performance of $\mathrm{H}-\mathrm{Mil}-88 \mathrm{~B}(\mathrm{Fe})$ and $\mathrm{Mil}-88 \mathrm{~B}(\mathrm{Fe})$ at different current densities. (D) The electrochemical impedance spectra (EIS) of H-Mil-88B(Fe) and Mil-88B(Fe).

the $\mathrm{H}-\mathrm{Mil}-88 \mathrm{~B}(\mathrm{Fe})$ electrode is almost twice higher than that of the Mil- $88 \mathrm{~B}(\mathrm{Fe})$ electrode. The reversible capacity of the H-Mil$88 \mathrm{~B}(\mathrm{Fe})$ electrode is $600.1 \mathrm{mAh} \mathrm{g}^{-1}$ after 100 cycles, while Mil$88 \mathrm{~B}(\mathrm{Fe})$ remains to have a capacity of $312.5 \mathrm{mAh} \mathrm{g}^{-1}$, suggesting that the high SSA can effectively enhance the specific capacity, and the novel $3 \mathrm{D}$ structure is beneficial to improve the cycling stability. Figure 4C explores the rate performance of the Mil$88 \mathrm{~B}(\mathrm{Fe})$ and $\mathrm{H}-\mathrm{Mil}-88 \mathrm{~B}(\mathrm{Fe})$ electrodes at the current densities of $50,100,200,500$, and $1,000 \mathrm{~mA} \mathrm{~g}^{-1}$. The reversible capacity of the H-Mil-88B(Fe) electrode is $640.5,446.3,267.5,142.8$, and $66.4 \mathrm{mAh} \mathrm{g}^{-1}$, respectively, while the Mil- $88 \mathrm{~B}(\mathrm{Fe})$ electrode delivers the capacities of $273.4,245.4,212,142.6$, and $83.6 \mathrm{mAh}^{-1}$, respectively. When the current density recovered to $50 \mathrm{~mA} \mathrm{~g}^{-1}$, the specific capacity can reach to 615.7 and $382.4 \mathrm{mAh} \mathrm{g}^{-1}$, respectively. Figure 4D illustrates the Nyquist plots of EIS for Mil- $88 \mathrm{~B}(\mathrm{Fe})$ and $\mathrm{H}-\mathrm{Mil}-88 \mathrm{~B}(\mathrm{Fe})$. Basically, the semicircle and the straight line represent the contact impedance and charge transfer resistance, and the spread resistance, respectively (Tang et al., 2018). Based on the simulation, the charge transfer resistance of the H-Mil$88 \mathrm{~B}(\mathrm{Fe})$ electrode is $212.8 \Omega$, which is much lower than that of the Mil- $88 \mathrm{~B}(\mathrm{Fe})$ electrode $(261.5 \Omega)$, indicating the higher activity and improved connectivity of the H-Mil- $88 \mathrm{~B}(\mathrm{Fe})$ electrode. To illuminate the prominent LIBs' performance of $\mathrm{H}-\mathrm{Mil}-88 \mathrm{~B}(\mathrm{Fe})$, the capacitive and diffusion-controlled contribution was explored by employing Eqs. 1, 2. The CV curves of the Mil-88B(Fe) and H-Mil-88B(Fe) electrodes at different scan rates are presented in Figures $\mathbf{5 A}, \mathbf{B}$, respectively. The cathodic and anodic peaks are preserved well under different sweep rates. As shown in Figure 5C, the $\mathrm{b}$ value for the Mil- $88 \mathrm{~B}(\mathrm{Fe})$ electrode is 0.535 , which suggests a diffusion-controlled mechanism. On the other hand, the b-value is 0.888 for the $\mathrm{H}-\mathrm{Mil}-88 \mathrm{~B}(\mathrm{Fe})$ electrode, demonstrating that the majority charge storage process is relating to capacitive characteristics (Ma et al., 2013; Shen et al., 2018), The total capacitive contribution to the current response can be calculated by Eq. 2. In Figure 5D, 69.14\% of the total capacity is symbolized as the capacitive contribution for the H-Mil-88B(Fe) electrode. Figures 5E, F draw the percentage of the capacitive contribution of the Mil- $88 \mathrm{~B}(\mathrm{Fe})$ and $\mathrm{H}-\mathrm{Mil}$ $88 \mathrm{~B}(\mathrm{Fe})$ electrode. It is found that the capacitive contribution gradually increases with the increase in scan rate. At the sweep rates of $0.2,0.4,0.6,0.8$, and $1 \mathrm{mV} \mathrm{s}^{-1}$, the capacitive contributions of $\mathrm{Mil}-88 \mathrm{~B}(\mathrm{Fe})$ are $18.00,20.81,25.10,31.78$, and $35.41 \%$, which indicate the diffusion-dominated process. Accordingly, the capacitive contributions of $\mathrm{H}-\mathrm{Mil}-88 \mathrm{~B}(\mathrm{Fe})$ are $47.60,53.28,56.88,74.68$, and $69.14 \%$, which illuminate the capacitance-controlled charge storage process. Thus, the high SSA, novel 3D nanostructure, and low impedance cause the high capacitive contribution of the $\mathrm{H}-\mathrm{Mil}-88 \mathrm{~B}(\mathrm{Fe})$ electrode, 

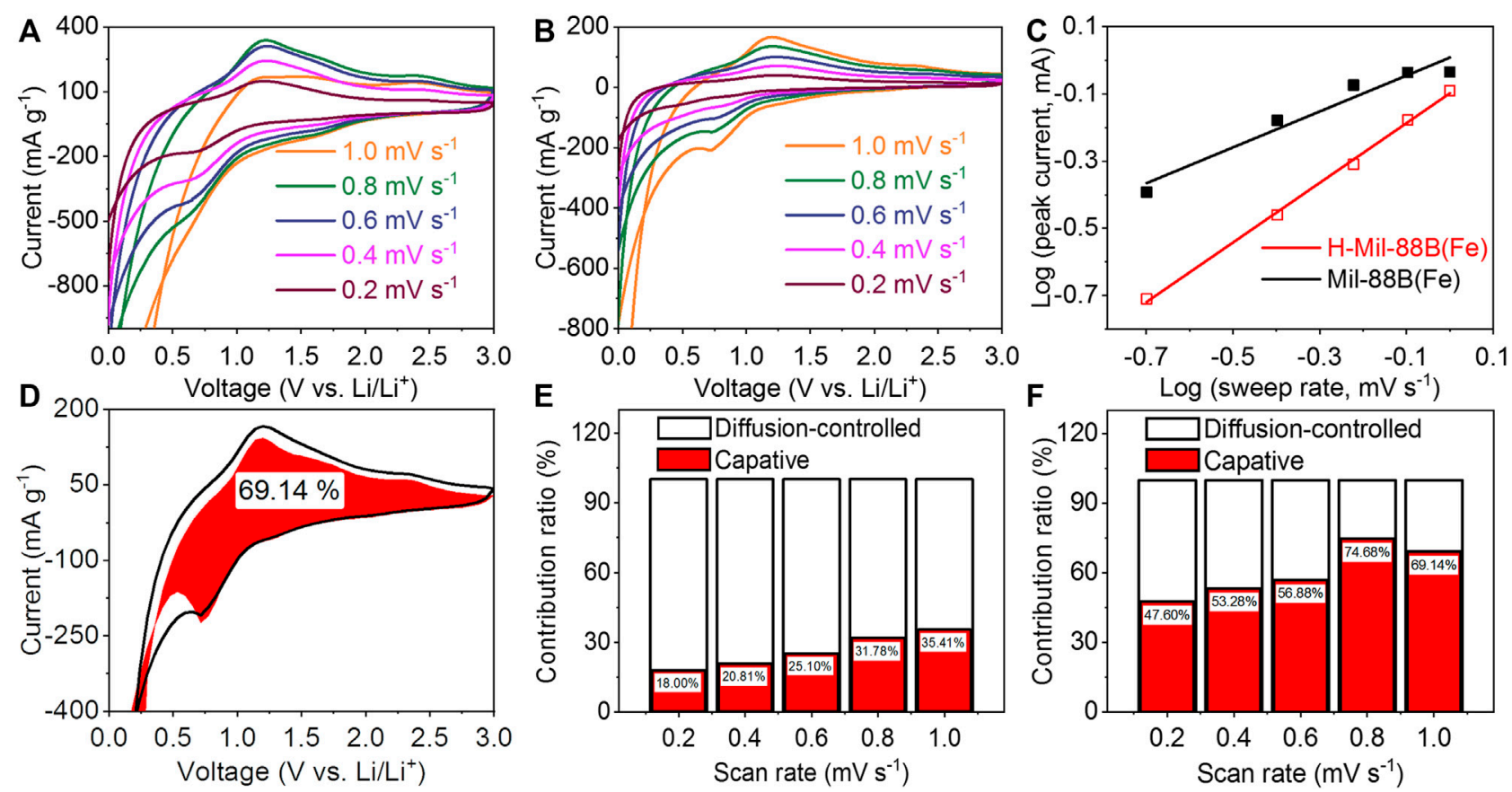

FIGURE 5 | CV curves of the Mil-88B(Fe) (A) and H-Mil-88B(Fe) (B) electrodes at different scan rates. (C) Determination of the b value according to the relationship between peak current and scan rate. (D) The capacitive contribution (red) of $1 \mathrm{mV} \mathrm{s}^{-1}$, normalized capacitive contribution of Mil-88B(Fe) (E) and $\mathrm{H}-\mathrm{Mil}-88 \mathrm{~B}(\mathrm{Fe})$ (F) electrodes at different scan rates.

indicating that it can afford the high current densities and thereby achieves a better rate capability.

\section{CONCLUSION}

In summary, we have prepared the modified Mil-88B(Fe) [H-Mil$88 \mathrm{~B}(\mathrm{Fe})]$ material by employing a hydrolysis method. H-Mil-88 exhibits a hollowed spindle-like structure, which facilitates the $\mathrm{Li}^{+}$ diffusion, electron transfer, and provides a large specific surface area for $\mathrm{Li}^{+}$storage. Benefiting from the unique structure, the H-Mil-88 electrode delivers a high reversible specific capacity of $600.1 \mathrm{mAh} \mathrm{g}^{-1}$ after 100 cycles at a current density of $100 \mathrm{~mA} \mathrm{~g}^{-1}$. Furthermore, it also displays moderate rate capability. The mechanism analysis demonstrates that the H-Mil-88 electrode realizes the enhanced capacitive behavior. Thus, this study proposes the novel strategy for the morphological engineering of Mil-88, which can be spanned to other MOFs for a highperformance energy storage device.

\section{REFERENCES}

Chang, X., Huang, T., Yu, J., Li, J., Wang, J., and Wei, Q. (2021). Pseudocapacitive Anode Materials toward High-Power Sodium-Ion Capacitors. Batteries. Supercaps 4, 1567-1587. doi:10.1002/batt.202100043

Chen, Y., Xiong, Z., Peng, L., Gan, Y., Zhao, Y., Shen, J., et al. (2015). Facile Preparation of Core-Shell Magnetic Metal-Organic Framework Nanoparticles

\section{DATA AVAILABILITY STATEMENT}

The original contributions presented in the study are included in the article. Further inquiries can be directed to the corresponding author.

\section{AUTHOR CONTRIBUTIONS}

HL contributed to the conception and design of the study. MG organized the database. MG wrote the first draft of the manuscript. HL revised the whole manuscript. All authors contributed to the article and approved the submitted version.

\section{FUNDING}

This work was supported by the Project of Ningxia Key R\&D Plan (2021BEE03006).

for the Selective Capture of Phosphopeptides. ACS Appl. Mater. Inter. 7 (30), 16338-16347. doi:10.1021/acsami.5b03335

Come, J., Taberna, P.-L., Hamelet, S., Masquelier, C., and Simon, P. (2011). Electrochemical Kinetic Study of LiFePO4 Using Cavity Microelectrode. J. Electrochem. Soc. 158 (10), A1090. doi:10.1149/1.3619791

Deng, H., Qiu, F., Li, X., Qin, H., Zhao, S., He, P., et al. (2017). A Li-Ion Oxygen Battery with Li-Si alloy Anode Prepared by a Mechanical Method. Electrochemistry Commun. 78, 11-15. doi:10.1016/j.elecom.2017.03.010 
Dou, Y., Zhang, W., and Kaiser, A. (2019). Electrospinning of Metal-Organic Frameworks for Energy and Environmental Applications. Adv. Sci. 7, 1902590. doi:10.1002/advs.201902590

Du, J.-J., Yuan, Y.-P., Sun, J.-X., Peng, F.-M., Jiang, X., Qiu, L.-G., et al. (2011). New Photocatalysts Based on MIL-53 Metal-Organic Frameworks for the Decolorization of Methylene Blue Dye. J. Hazard. Mater. 190, 945-951. doi:10.1016/j.jhazmat.2011.04.029

Du, Y., Ma, W., and Li, H. (2020). In Situ Growth of CoP 3/Carbon Polyhedron/ $\mathrm{CoO} / \mathrm{NF}$ Nanoarrays as Binder-Free Anode for Lithium-Ion Batteries with Enhanced Specific Capacity. Small 16, 1907468. doi:10.1002/smll.201907468

Férey, G., Millange, F., Morcrette, M., Serre, C., Doublet, M.-L., Grenèche, J.-M., et al. (2007). Mixed-Valence Li/Fe-Based Metal-Organic Frameworks with Both Reversible Redox and Sorption Properties. Angew. Chem. Int. Ed. 46, 3259-3263. doi:10.1002/anie.200605163

Guo, M., and Li, H. (2021). Enhancing the Li+ Diffusion in Li3VO4by Coupling Withreduced Graphene Oxide for Lithium-Ion Batteries. Cnano 17, 1-7. doi:10.2174/1573413717666210202115508

Hu, C., Yoshida, M., Huang, P.-H., Tsunekawa, S., Hou, L.-B., Chen, C.-H., et al. (2021). MIL-88B(Fe)-coated Photocatalytic Membrane Reactor with Highly Stable Flux and Phenol Removal Efficiency. Chem. Eng. J. 418, 129469. doi:10.1016/j.cej.2021.129469

Huang, Y., Liu, C., Wei, F., Wang, G., Xiao, L., Lu, J., et al. (2020). Chemical Prelithiation of $\mathrm{Al}$ for Use as an Ambient Air Compatible and Polysulfide Resistant Anode for Li-Ion/S Batteries. J. Mater. Chem. A. 8, 18715-18720. doi:10.1039/D0TA06694J

Jin, Y., Zhao, C., Lin, Y., Wang, D., Chen, L., and Shen, C. (2017). Fe-Based MetalOrganic Framework and its Derivatives for Reversible Lithium Storage. J. Mater. Sci. Tech. 33 (8), 768-774. doi:10.1016/j.jmst.2016.11.021

Li, D., Dai, P., Chen, Y., Peng, R., Sun, Y., and Zhou, H. (2018). Lithium Borocarbide LiBC as an Anode Material for Rechargeable Li-Ion Batteries. J. Phys. Chem. C. 122 (32), 18231-18236. doi:10.1021/acs.jpcc.8b03763

Liu, C., Sun, Q., Lin, L., Wang, J., Zhang, C., Xia, C., et al. (2020). Ternary MOFOn-MOF Heterostructures with Controllable Architectural and Compositional Complexity via Multiple Selective Assembly. Nat. Commun. 11, 4971. doi:10.1038/s41467-020-18776-Z

Luo, B., Yang, M., Jiang, P., Lan, F., and Wu, Y. (2016). Multi-affinity Sites of Magnetic Guanidyl-Functionalized Metal-Organic Framework Nanospheres for Efficient Enrichment of Global Phosphopeptides. Nanoscale 10 (18), 8391-8396. doi:10.1039/C8NR01914B

Ma, M., Bétard, A., Weber, I., Al-Hokbany, N. S., Fischer, R. A., and Metzler-Nolte, N. (2013). Iron-Based Metal-Organic Frameworks MIL-88B and NH2-MIL88B: High Quality Microwave Synthesis and Solvent-Induced Lattice "Breathing". Cryst. Growth Des. 13, 2286-2291. doi:10.1021/cg301738p

Ming, J., Cao, Z., Wahyudi, W., Li, M., Kumar, P., Wu, Y., et al. (2018). New Insights on Graphite Anode Stability in Rechargeable Batteries: Li Ion Coordination Structures Prevail over Solid Electrolyte Interphases. ACS Energ. Lett. 3 (3), 335-340. doi:10.1021/acsenergylett.7b01177

Pan, X., Duan, X., Lin, X., Zong, F., Tong, X., Li, Q., et al. (2018). Rapid Synthesis of Cr-Doped $\gamma$-Fe2O3/reduced Graphene Oxide Nanocomposites as High Performance Anode Materials for Lithium Ion Batteries. J. Alloys Comp. 732, 270-279. doi:10.1016/j.jallcom.2017.10.222

Rao, P. C., and Mandal, S. (2019). Potential Utilization of Metal-Organic Frameworks in Heterogeneous Catalysis: A Case Study of Hydrogen-Bond Donating and Single-Site Catalysis. Chem. Asian J. 14, 4087-4102. doi:10.1002/ asia.201900823

Shang, X., Liu, Z., Ji, W., and Li, H. (2021). Synthesis of Lithium Vanadate/reduced Graphene Oxide with strong Coupling for Enhanced Capacitive Extraction of Lithium Ions. Separat. Purif. Tech. 262, 118294. doi:10.1016/j.seppur.2020.118294

Shen, L., Song, H., and Wang, C. (2017). Metal-Organic Frameworks Triggered High-Efficiency Li Storage in Fe-Based Polyhedral Nanorods for Lithium-Ion Batteries. Electrochimica Acta. 235, 595-603. doi:10.1016/ j.electacta.2017.03.105

Shen, L., Wang, Y., Lv, H., Chen, S., van Aken, P. A., Wu, X., et al. (2018). Ultrathin Ti2 Nb2 O9 Nanosheets with Pseudocapacitive Properties as Superior Anode for Sodium-Ion Batteries. Adv. Mater. 30, 1804378. doi:10.1002/ adma.201804378

Shen, Z., Zhao, C., Hu, Z., Fu, C., Lv, f., and Lin, Q. (2021). Synthesis of Fe3Se4/ carbon Composites from Different Metal-Organic Frameworks and Their
Comparative Lithium/sodium Storage Performances. Chem. Pap. 75, 2737-2747. doi:10.1007/s11696-021-01524-y

Tang, Y., Zhang, Y., Malyi, O. I., Bucher, N., Xia, H., Xi, S., et al. (2018). Identifying the Origin and Contribution of Surface Storage in TiO2 (B) Nanotube Electrode by In Situ Dynamic Valence State Monitoring. Adv. Mater. 30, 1802200. doi:10.1002/adma.201802200

Wang, B., Liu, B., Yan, Y., Tang, K., and Ding, C.-F. (2019). Binary Magnetic MetalOrganic Frameworks Composites: a Promising Affinity Probe for Highly Selective and Rapid Enrichment of Mono- and Multi-Phosphopeptides. Microchim Acta 186, 832. doi:10.1007/s00604-019-3916-5

Wang, C., An, B., and Lin, W. (2019). Metal-Organic Frameworks in Solid-Gas Phase Catalysis. ACS Catal. 9 (1), 130-146. doi:10.1021/acscatal.8b04055

Wang, H., Zhang, N., Li, S., Ke, Q., Li, Z., and Zhou, M. (2020). Metal-organic Framework Composites for Energy Conversion and Storage. J. Semicond. 41, 091707. doi:10.1088/1674-4926/41/9/091707

Wang, Y., and Cao, G. (2008). Developments in Nanostructured Cathode Materials for High-Performance Lithium-Ion Batteries. Adv. Mater. 20, 2251-2269. doi:10.1002/adma.200702242

Wang, Z., Dang, G. J., Zhang, Q. S., and Xie, J. Y. (2017). Xanthan Gum as a Potential Binder for Graphite Anode in Lithium-Ion Batteries. Int. J. Electrochem. Sci. 12, 7457-7468. doi:10.20964/2017.08.55

Wang, Z., Wu, C., Zhang, Z., Chen, Y., Deng, W., and Chen, W. (2021). Bimetallic Fe/Co-MOFs for Tetracycline Elimination. J. Mater. Sci. 56, 15684-15697. doi:10.1007/s10853-021-06280-8

Wei, Q., DeBlock, R. H., Butts, D. M., Choi, C., and Dunn, B. (2020). Pseudocapacitive Vanadium-based Materials toward High-Rate Sodium-Ion Storage. Energy Environ. Mater. 3, 221-234. doi:10.1002/eem2.12131

Xi, X.-T., Feng, X., Nie, X.-J., Hou, B.-H., Li, W.-H., Yang, X., et al. (2019). Dendrite-free Deposition on Lithium Anode toward Long-Life and High-Stable Li//graphite Dual-Ion Battery. Chem. Commun. 55, 8406-8409. doi:10.1039/ C9CC03175H

Xia, H., Tang, Y., Malyi, O. I., Zhu, Z., Zhang, Y., Zhang, W., et al. (2021). Deep Cycling for High-Capacity Li-Ion Batteries. Adv. Mater. 33, 2004998. doi:10.1002/adma.202004998

Xu, H., Liu, M., Huang, X., Min, Q., and Zhu, J.-J. (2018). Multiplexed Quantitative MALDI MS Approach for Assessing Activity and Inhibition of Protein Kinases Based on Postenrichment Dephosphorylation of Phosphopeptides by MetalOrganic Framework-Templated Porous CeO2. Anal. Chem. 90 (16) 9859-9867. doi:10.1021/acs.analchem.8b01938

Xu, J., Dou, Y., Wei, Z., Ma, J., Deng, Y., Li, Y., et al. (2017). Recent Progress in Graphite Intercalation Compounds for Rechargeable Metal (Li, Na, K, Al)-Ion Batteries. Adv. Sci. 4, 1700146. doi:10.1002/advs.36510.1002/advs.201700146

Xu, M., Yang, S. S., Gu, Z. Y., and Gu, Z. Y. (2018). Two-Dimensional MetalOrganic Framework Nanosheets: A Rapidly Growing Class of Versatile Nanomaterials for Gas Separation, MALDI-TOF Matrix and Biomimetic Applications. Chem. Eur. J. 24, 15131-15142. doi:10.1002/ chem.201800556

Yang, R., Wang, Y., Deng, Q., Hui, P., Luo, Z., Yan, Y., et al. (2021). Metalorganic Framework Derived Fe3O4/C/rGO Composite as an Anode Material in Lithium-Ion Batteries. Ionics 27, 3281-3289. doi:10.1007/s11581-02104143-5

Yang, S.-S., Chang, Y.-J., Zhang, H., Yu, X., Shang, W., Chen, G.-Q., et al. (2018). Enrichment of Phosphorylated Peptides with Metal-Organic Framework Nanosheets for Serum Profiling of Diabetes and Phosphoproteomics Analysis. Anal. Chem. 90 (22), 13796-13805. doi:10.1021/ acs.analchem.8b04417

Zhang, C., Hu, W., Jiang, H., Chang, J.-K., Zheng, M., Wu, Q.-H., et al. (2017). Electrochemical Performance of MIL-53(Fe)@RGO as an Organic Anode Material for Li-Ion Batteries. Electrochimica Acta 246, 528-535. doi:10.1016/ j.electacta.2017.06.059

Zhang, S., Zhuo, Y., Ezugwu, C. I., Wang, C.-c., Li, C., and Liu, S. (2021). Synergetic Molecular Oxygen Activation and Catalytic Oxidation of Formaldehyde over Defective MIL-88B(Fe) Nanorods at Room Temperature. Environ. Sci. Technol. 55 (12), 8341-8350. doi:10.1021/acs.est.1c01277

Zhang, X., Li, J., Han, L., Li, H., Wang, J., Lu, T., et al. (2021). In-situ Fabrication of Few-Layered MoS2 Wrapped on TiO2-Decorated MXene as Anode Material for Durable Lithium-Ion Storage. J. Colloid Interf. Sci. 604, 30-38. doi:10.1016/ j.jcis.2021.07.013 
Zhu, Y., Li, G., Luo, D., Wan, H., Feng, M., Yuan, D., et al. (2021). Unsaturated Coordination Polymer Frameworks as Multifunctional Sulfur Reservoir for Fast and Durable LithiumSulfur Batteries. Nano Energy 79, 105393. doi:10.1016/j.nanoen.2020.105393

Conflict of Interest: The authors declare that the research was conducted in the absence of any commercial or financial relationships that could be construed as a potential conflict of interest.

Publisher's Note: All claims expressed in this article are solely those of the authors and do not necessarily represent those of their affiliated organizations, or those of the publisher, the editors, and the reviewers. Any product that may be evaluated in this article, or claim that may be made by its manufacturer, is not guaranteed or endorsed by the publisher.

Copyright (c) 2021 Guo and Li. This is an open-access article distributed under the terms of the Creative Commons Attribution License (CC BY). The use, distribution or reproduction in other forums is permitted, provided the original author(s) and the copyright owner(s) are credited and that the original publication in this journal is cited, in accordance with accepted academic practice. No use, distribution or reproduction is permitted which does not comply with these terms. 